\title{
Sistematização participativa de cursos de capacitação em solos para professores da educação basica
}

\author{
Participatory systematization OF tRaining COURSES ON SOILS FOR Basic SCHOOL TEACHeRS \\ Fernanda Oliveira Cirino ${ }^{1}$, Cristine Carole Muggler ${ }^{2}$, Irene Maria Cardoso ${ }^{2}$ \\ 1-Instituto de Ciências Agrárias, Universidade Federal de Minas Gerais, Montes Claros, MG. fernanda_cirino@yahoo.com.br \\ 2-Departamento de Solos, Universidade Federal de Viçosa, MG.
}

\section{Manuscrito:}

Recebido: $21 / 7 / 2013$

Corrigido: $22 / 11 / 2013$

Aceito: 9/9/2014

Citation: Perez C.P., Andrade L.C. Rodrigues M.F. 2015. Sistematização participativa de cursos de capacitação em solos para professores da educação básica. Terræ Didatica, 11(1):21-32. < http://www.ige. unicamp.br/terraedidatica/ $>$.

Keywords: soil education, basic education, teacher training

\begin{abstract}
Since 2004 the Soil and Environment Education Programme at the Soil Department of the Federal University of Viçosa offers annual training courses on soils and environment for primary and secondary schools teachers. After three years, the impacts of this approach in some schools in Viçosa-MG could be observed. The research designed to analyse and reflect about the influence of the courses in the pedagogical practices of the participants employed a participatory systematization process, involving meetings with participants of the 2004, 2005 and 2006 courses. The results presented in this article show that both content and methods developed in the courses were effectively appropriated by educators, who valued and gave a new meaning to the contents of the Educators were more confident and were able to enrich and diversify their classes with different methodological support for their classes.
\end{abstract}

\section{Introdução}

Conteúdos de solos são pouco abordados pelos professores da Educação Básica, embora façam parte dos currículos e estejam presentes nos livros didáticos. Muitos professores os consideram complexos e de difícil abordagem, uma vez que envolvem conhecimentos específicos de diferentes disciplinas. Isso se dá em decorrência de deficiências tanto conceituais quanto pedagógicas relacionadas à sua formação profissional (Costa Falcão 2007; Falconi 2004). Ao mesmo tempo os livros didáticos apresentam os conteúdos de solos de forma fragmentada e descontextualizada, quando não equivocada (Muggler et al. 2006).

Nesse contexto, e considerando os desafios que a atual produção e disseminação do conhecimento colocam para a educação, os programas de formação continuada de professores são uma necessidade, uma vez que a sua formação inicial não abrange de forma suficiente todos os conhecimentos necessários à sua prática docente. Além disso, a velocidade da transformação de conceitos, incluindo métodos de trabalho, contribui para a necessidade constante de atualizações conceituais e metodológicas (Lima e Vasconcelos 2008). Considerando a importância de atualizar e capacitar professores em exercício em temas ambientais, com ênfase para solos, o Programa de Educação em Solos e Meio Ambiente (PES) do Museu de Ciências da Terra Alexis Dorofeef do Departamento de Solos da Universidade Federal de Viçosa, oferece oficinas para educadores da Educação Básica desde 2000. A partir de 2004, o conjunto de oficinas foi organizado em um curso anual intitulado "Desenvolvimento de Conteúdos e Métodos de Abordagem em Solos e Meio Ambiente". Os cursos foram estruturados em oficinas presenciais mensais, complementadas com o desenvolvimento de projeto pedagógico pelos cursistas em suas escolas, com a orientação e acompanhamento da equipe coordenadora dos cursos. O Quadro 1 apresenta o programa dos cursos dos anos de 2004, 2005 e 2006. 
Quadro 1. Temas, carga horária e objetivos das oficinas do curso de capacitação de professores realizado no ano de 2006

\begin{tabular}{|c|c|c|c|}
\hline Oficina & Tema/conteúdo & $\begin{array}{l}\text { Carga } \\
\text { horária }\end{array}$ & Objetivos \\
\hline 1 & $\begin{array}{l}\text { Solos e Meio } \\
\text { Ambiente: Introdução }\end{array}$ & 4 horas & $\begin{array}{l}\text { Reconhecer os ambientes de vivência como instrumento de abordagem } \\
\text { do tema solos. }\end{array}$ \\
\hline 2 & $\begin{array}{l}\text { Solos, Rochas e } \\
\text { Minerais }\end{array}$ & 8 horas & $\begin{array}{l}\text { Construir, de forma integrada, os conceitos básicos sobre minerais e } \\
\text { rochas enquanto materiais de origem do solo. }\end{array}$ \\
\hline 3 & $\begin{array}{l}\text { Recursos naturais: } \\
\text { Uso e Impactos } \\
\text { Ambientais }\end{array}$ & 4 horas & $\begin{array}{l}\text { (Re) conhecer e diferenciar os recursos naturais, caracterizando-os, } \\
\text { compreendendo o seu uso e a sua importância e avaliando os impactos } \\
\text { ambientais gerados a partir da sua utilização. }\end{array}$ \\
\hline 4 & $\begin{array}{l}\text { Vida e Atributos do } \\
\text { Solo }\end{array}$ & 8 horas & $\begin{array}{l}\text { (Re) conhecer e diferenciar características e propriedades dos solos, } \\
\text { a partir da compreensão do seu modo de formação e perceber e } \\
\text { compreender as interações existentes entre o solo e os seres vivos. }\end{array}$ \\
\hline 5 & O Solo na Paisagem & 4 horas & $\begin{array}{l}\text { Exercitar a análise e a percepção integrada de diversos aspectos } \\
\text { ambientais de uma microbacia hidrográfica. }\end{array}$ \\
\hline 6 & $\begin{array}{l}\text { Uso e Conservação } \\
\text { dos Solos }\end{array}$ & 4 horas & $\begin{array}{l}\text { Perceber, analisar e avaliar as formas e os impactos gerados no uso e } \\
\text { ocupação dos solos, discutindo a sua conservação na perspectiva da } \\
\text { Agroecologia. }\end{array}$ \\
\hline 7 & $\begin{array}{l}\text { Principais Solos do } \\
\text { Brasil }\end{array}$ & 8 horas & $\begin{array}{l}\text { (Re)conhecer os principais tipos de solos brasileiros, a partir } \\
\text { da compreensão dos aspectos que influenciam a sua formação, } \\
\text { caracterizando as potencialidades de uso e impactos ambientais. }\end{array}$ \\
\hline \multirow[t]{3}{*}{8} & $\begin{array}{l}\text { Solos e Meio } \\
\text { Ambiente }\end{array}$ & 4 horas & $\begin{array}{l}\text { Exercitar a análise e percepção ambiental a partir do espaço do entorno } \\
\text { de uma escola e sintetizar e avaliar o incremento da percepção do solo } \\
\text { como parte essencial do meio ambiente, ao longo do curso. }\end{array}$ \\
\hline & $\begin{array}{l}\text { Elaboração e } \\
\text { desenvolvimento de } \\
\text { projeto pedagógico }\end{array}$ & 44 horas & $\begin{array}{l}\text { Elaborar e desenvolver um projeto pedagógico relacionado à temática } \\
\text { do curso. }\end{array}$ \\
\hline & Encontro de avaliação & 4 horas & $\begin{array}{l}\text { Realizar uma avaliação de todo o curso, envolvendo análises dos } \\
\text { conteúdos abordados, das metodologias e materiais didáticos utilizados, } \\
\text { e os projetos pedagógicos elaborados e/ou desenvolvidos pelos cursistas. }\end{array}$ \\
\hline
\end{tabular}

Fonte: Arquivo Museu de Ciências da Terra Alexis Dorofeef, 2007 e 2008

Após três anos consecutivos de realização dos cursos, já era possível observar alguns impactos dessa abordagem em algumas escolas de Viçosa (MG), o que se dava, entretanto, de forma pontual e esporádica, sem, no entanto se ter claro de como e em que extensão isso se dava (Cirino 2008). Assim, foi concebida uma pesquisa cuja pergunta inicial foi: o curso proporcionou alguma mudança nas práticas dos professores? Para isso, foi proposta, planejada e desenvolvida uma sistematização participativa para levantar e avaliar os resultados e impactos dos cursos dos anos de 2004, 2005 e 2006. A sistematização participativa além de organizar, analisar e classificar as informações permite o envolvimento dos sujeitos que participaram das experiências através do compartilhamento, das vivências e conhecimentos de cada um (Holliday 2006).

Além da pergunta inicial, a pesquisa buscou responder às seguintes questões específicas: 1 . Os educadores passaram a trabalhar e abordar mais conteúdos de solos? 2. Os educadores consegui- ram modificar a sua visão e ideia de complexidade e inacessibilidade do tema solos? 3. Os conteúdos de solos passaram a ser abordados de forma mais significativa e com a utilização de métodos mais motivadores? 4. Os educadores foram sensibilizados e compreenderam a importância ambiental dos solos? Essas perguntas foram sendo respondidas ao longo de toda a sistematização e suas respostas encontram-se nos resultados.

\section{Material e Métodos}

O desenvolvimento da pesquisa foi estruturado em duas etapas principais, no formato de uma sistematização participativa: visita e entrevista semiestruturada com educadores (professores, professoras, diretoras, coordenadoras pedagógicas e uma agente comunitária) que realizaram os cursos nos anos de 2004, 2005 e 2006, e a realização de três encontros coletivos com a participação de apenas educadoras que se disponibilizaram a 
participar de todos os encontros. O fato de serem todas mulheres é apenas um reflexo da participação majoritária destas nos cursos (nos três anos houve a participação de apenas quatro homens). Inicialmente foi feito o levantamento dos nomes e endereços dos educadores que participaram dos três cursos, que foram então contatados e informados sobre a pesquisa. As visitas e entrevistas semiestruturadas foram realizadas no local de trabalho de cada um. Para a realização das entrevistas foi elaborado um roteiro com perguntas gerais (Almeida 1989) que possibilitasse uma conversa aberta e detalhada sobre as possibilidades/potencialidades e desafios da abordagem de conteúdos de solos, e a influência da realização do curso na percepção conceitual e na prática pedagógica dos educadores.

Os encontros coletivos aconteceram em dias de sábado, no Museu de Ciências da Terra Alexis Dorofeef, mesmo espaço onde se realizaram os cursos. Nos encontros coletivos foram utilizadas técnicas participativas adequadas aos objetivos específicos de cada encontro. No primeiro encontro foi utilizada a técnica da Linha do Tempo (Geilfus 2000) com o objetivo de resgatar os cursos e seus desdobramentos e, assim, possibilitar a reflexão sobre os seus impactos nas práticas pedagógicas das participantes. O segundo encontro teve como objetivos o levantamento e análise dos conteúdos e dos métodos de abordagem de solos utilizados pelas participantes em sua atuação profissional. O encontro foi desenvolvido em duas etapas. A primeira consistiu em levantar, discutir e relacionar os conteúdos de solos e outros que permitem sua abordagem, através da construção de um Diagrama de Venn (Geilfus 2000). A segunda buscou levantar coletivamente os métodos de abordagem e com que frequência e para quais conteúdos foram utilizados pelas educadoras, com a construção de uma Matriz de Conteúdos e Métodos (Geilfus 2000). Para o terceiro encontro a equipe de sistematização desenvolveu uma metodologia que foi denominada Avaliação Coletiva. Nesta, os resultados obtidos até então foram organizados e sintetizados para que as participantes pudessem conhecer, analisar e avaliar o conjunto coletivamente e, assim, sugerir, complementar e alterar interpretações que foram feitas no processo da sistematização. Ao mesmo tempo foram levantadas e sintetizadas as lições e aprendizados adquiridos durante o processo. A adaptação e o desenvolvimento das estratégias metodológicas acima descritas também faz parte dos resultados desse trabalho.

\section{Resultados e Discussão}

\section{Entrevistas}

Trinta e quatro educadores participaram dos cursos realizados nos anos de 2004 a 2006. Destes, vinte e sete se disponibilizaram a serem visitados e entrevistados. Dos vinte e sete entrevistados, apenas quatro professores mostraram-se pouco interessados pela pesquisa e não fizeram citações ou demonstrações com alguma prática adquirida no curso. A justificativa que prevaleceu entre esses quatro entrevistados é de que as dificuldades encontradas no dia-a-dia da escola (por exemplo, salas de aula superlotadas e carga horária de trabalho exaustiva) não permite o aprofundamento de conteúdos como o de solos. Por outro lado, a maioria dos entrevistados mostrou-se disposta a mudar a sua realidade, e o fez, mostrando resultados práticos, nos quais os cursos de capacitação em solos foram um importante suporte e apoio a estes educadores em suas intervenções.

Em relação à abordagem de conteúdos de solos antes e depois do curso (Quadro 2), constatou-se que essa era limitada principalmente por uma percepção de dificuldade e complexidade do conteúdo. Entre outros, o fato de que os temas relacionados a solos envolvem conhecimentos de Química, de Física e de Biologia tornavam-no mais difícil para alguns professores, limitando o seu ensino. Nas entrevistas, despertou atenção a importância da compreensão da origem e formação do solo. Para muitos educadores, antes do curso as rochas não eram percebidas como produtos geológicos que dão origem ao solo, e não havia o conhecimento integrado dos fatores que atuam no seu processo de formação. Esta também foi uma constatação feita por Sobrinho (2005) ao realizar um diagnóstico sobre ensino e aprendizagem de conteúdos de solos com um grupo de professores da educação básica. Além dessas dificuldades conceituais, os educadores enfrentavam o problema de como trabalhar com seus alunos de forma dinâmica e prática um tema que consideravam difícil, complexo e/ou abstrato demais. Mesmo aqueles que possuíam conhecimentos pedológicos mais consistentes apontaram dificuldades em relação à maneira de abordar o conteúdo (Quadro 3). Na maioria dos casos, o ensino era feito apenas com o suporte do livro didático, através de aula expositiva e sem nenhuma atividade prática. A abordagem seguia o livro, sem nenhuma análise e avaliação crítica por 
Sistematização participativa de cursos de capacitação em solos para professores da educação básica

Quadro 2. Respostas dos entrevistados relativas à abordagem de conteúdos de solos antes e após a realização do curso de capacitação

\begin{tabular}{|c|c|}
\hline \multicolumn{2}{|c|}{ Quanto ao conteúdo } \\
\hline Antes do Curso & Depois do Curso \\
\hline $\begin{array}{l}\text { "Achava o conteúdo difícil de ser trabalhado com os } \\
\text { meninos, eu não sabia a diferença de rocha pra mineral, } \\
\text { e nem sabia como o solo se formava" }\end{array}$ & $\begin{array}{l}\text { "Passei a entender a dinâmica de formação do solo e as } \\
\text { diferenças de rochas e minerais, sinto que tenho mais } \\
\text { dominio e segurança e os alunos percebem isso. Faço mais } \\
\text { discussões e isso gera muitos questionamentos por parte } \\
\text { dos alunos" }\end{array}$ \\
\hline $\begin{array}{l}\text { "Não compreendia muito bem, pra mim era tão difícil } \\
\text { que nem me esforçava para entender, passava o que } \\
\text { tinha que passar para os alunos..." }\end{array}$ & $\begin{array}{l}\text { "Agora compreendo o conteúdo, tornou-se importante } \\
\text { pra mim e tento passar isto para meus alunos, me sinto } \\
\text { mais segura pra ensinar porque agora entendo o que estou } \\
\text { ensinando, é diferente" }\end{array}$ \\
\hline "Ficava muito limitada antes" & $\begin{array}{l}\text { "Tenho mais segurança no conteúdo aí saio inventando } \\
\text { um monte de coisas..." }\end{array}$ \\
\hline $\begin{array}{l}\text { "O conteúdo é complicado, me dava desânimo na } \\
\text { hora que chegava nesta parte, as vezes eu só dava uma } \\
\text { pincelada e já partia para o assunto seguinte” }\end{array}$ & $\begin{array}{l}\text { "Como mudou minha visão em relação ao assunto de } \\
\text { solos, ainda acho que é um conteúdo difícil, porque tem } \\
\text { que saber muita química, mas da maneira como vimos } \\
\text { lá no curso, dá para trabalhar de diferentes modos, e as } \\
\text { crianças adoram..." }\end{array}$ \\
\hline $\begin{array}{l}\text { "Achava que não tinha nada a ver ensinar os tipos de } \\
\text { rochas" }\end{array}$ & $\begin{array}{l}\text { "Agora sei que é da rocha que o solo é formado e suas } \\
\text { características vão depender da rocha que o formou, agora } \\
\text { ensino que a mãe do solo é a rocha..." }\end{array}$ \\
\hline $\begin{array}{l}\text { "Eu nunca tinha estudado sobre o assunto desta } \\
\text { maneira, por isso nunca dei importância" }\end{array}$ & $\begin{array}{l}\text { "Agora que aprendi como o solo é formado, suas } \\
\text { características, as diferenças das suas cores, tudo mudou, } \\
\text { ficou mais claro e gostoso de trabalhar com os meninos" }\end{array}$ \\
\hline $\begin{array}{l}\text { "Sinceramente parecia que não era voltado para os } \\
\text { alunos..." }\end{array}$ & "Trabalho com alunos quase tudo que aprendi no curso..." \\
\hline $\begin{array}{l}\text { "Eu não trabalhava o assunto, solos era matéria de } 3^{a} \\
\text { série e eu estava na } 1^{a}, 2^{a "}\end{array}$ & $\begin{array}{l}\text { "Hoje vejo que pode ser trabalhado desde a educação } \\
\text { infantil, o curso me deu esta abertura" }\end{array}$ \\
\hline $\begin{array}{l}\text { "Sempre tive dificuldades em ensinar este assunto, então } \\
\text { deixava para as professoras do ano seguinte ensinar..." }\end{array}$ & $\begin{array}{l}\text { "Agora eu mesmo ensino para meus alunos, é muito bom, } \\
\text { eles adoram, principalmente quando realizado a atividade } \\
\text { prática de verificar qual solo é mais arenoso, qual é mais } \\
\text { argiloso....." }\end{array}$ \\
\hline $\begin{array}{l}\text { "Não o via como conteúdo complexo de ensinar porque } \\
\text { não tive nada específico sobre o solo, pra mim era coisa } \\
\text { simples" }\end{array}$ & $\begin{array}{l}\text { "Lá nas oficinas do curso a gente vivenciava, era a prática } \\
\text { mesmo, então vi que ficar só no livro é muito superficial, } \\
\text { aí mostrar o solo lá de outra região... com fotografias é } \\
\text { muito difícil temos que trabalhar o dia-a-dia, o ambiente } \\
\text { que o aluno está inserido. Aproveitei do curso o trabalho } \\
\text { com o entorno da escola, ainda mais que é zona rural" }\end{array}$ \\
\hline "Como não tinha aquela base teórica, deixava pra lá..." & $\begin{array}{l}\text { "Tenho que preparar bem as aulas antes pra saber usar os } \\
\text { termos com cada série, eles adoram quando descobrem que } \\
\text { a pedra se transforma em terra, passei a trabalhar muito } \\
\text { com a observação" }\end{array}$ \\
\hline
\end{tabular}

parte dos educadores. A partir do momento em que os educadores ganharam conhecimento e segurança em relação à abordagem de solos, o livro deixou de ser a sua única ferramenta de trabalho, e eles passaram a diversificar as suas aulas com diferentes atividades práticas e passaram a considerá-las essenciais para o processo ensino-aprendizagem. As metodologias empregadas no curso foram muito significativas para o grupo, que passou a utilizá-las de forma direta ou adaptada em suas aulas. 
Quadro 3. Respostas dos entrevistados relativas à abordagem de conteúdos de solos em relação à metodologia e materiais utilizados antes e após a realização do curso de capacitação

\begin{tabular}{|c|c|}
\hline \multicolumn{2}{|c|}{ Quanto à metodologia e materiais didáticos } \\
\hline Antes do Curso & Depois do Curso \\
\hline $\begin{array}{l}\text { "Ah, passava superficialmente pelo assunto sem } \\
\text { uma atividade prática" }\end{array}$ & $\begin{array}{l}\text { "Faço tudo que aprendi lá no curso, levo os meninos pra ver o } \\
\text { barranco, mostro o gnaisse e faço atividades de textura, pintando } \\
\text { com o solo... são tantas coisas, que percebi que acabo dando mais } \\
\text { ênfase a este conteúdo que outros..." }\end{array}$ \\
\hline $\begin{array}{l}\text { "O ensino era com figuras, com colagens e eu ficava } \\
\text { lendo o tempo todo e não entendia como poderia } \\
\text { dar uma atividade prática" }\end{array}$ & $\begin{array}{l}\text { "Conto a história da Petrina1, levo o gnaisse, o basalto, o granito } \\
\text { e os meninos adoram..." }\end{array}$ \\
\hline $\begin{array}{l}\text { "O ensino sobre solos era predominantemente } \\
\text { teórico" }\end{array}$ & $\begin{array}{l}\text { "Hoje procuro abordar o assunto aproximando-o o máximo com } \\
\text { as experiências, vivência e observações que os alunos fazem do } \\
\text { meio em que vivem" }\end{array}$ \\
\hline $\begin{array}{l}\text { "Era apenas com o livro que a escola oferecia, } e \\
\text { achava difícil por falta de materiais..." }\end{array}$ & $\begin{array}{l}\text { "Percebi que os materiais estavam em qualquer lugar que } \\
\text { passamos, porque solos existem em todos os lugares..." }\end{array}$ \\
\hline $\begin{array}{l}\text { "Já sabia o conteúdo por causa do curso superior, } \\
\text { mas como formei em Zootecnia tinha dificuldades } \\
\text { didáticas" }\end{array}$ & $\begin{array}{l}\text { "Passei a trabalhar com atividades práticas como aquela da Vida } \\
\text { no Solo... mas ainda possuo algumas dificuldades" }\end{array}$ \\
\hline $\begin{array}{l}\text { "É um tema que gera dúvida na hora de ensinar, } \\
\text { não sabia a parte prática" }\end{array}$ & $\begin{array}{l}\text { "Tentei mudar um pouco o jeito de ensinar, e realizo algumas } \\
\text { atividades que aprendi como a (oficina) Vida no Solo, e a oficina } \\
\text { de Solos e Seus Atributos" }\end{array}$ \\
\hline $\begin{array}{l}\text { "Era muito abstrato, ensinava superficialmente sem } \\
\text { atividades práticas" }\end{array}$ & $\begin{array}{l}\text { "Uso atividades mais lúdicas com as crianças, como a pintura com } \\
\text { o solo, porque são muito pequenininhas ainda" }\end{array}$ \\
\hline $\begin{array}{l}\text { "Falava com os alunos o que estava no livro, } \\
\text { achava que era aquilo e pronto" }\end{array}$ & $\begin{array}{l}\text { "Descobri que tinha muita coisa que eu não sabia, vi que tem } \\
\text { várias formas de trabalhar além do livro" }\end{array}$ \\
\hline $\begin{array}{l}\text { "Ficava muito limitada ao livro, pra mim era } \\
\text { aquilo que tava lá }\end{array}$ & $\begin{array}{l}\text { "Nossa.. tem tanta coisa que eu não sabia e que não aparece no } \\
\text { livro, as vezes ensinava porque já tinha decorado daquele jeito, } \\
\text { não entendia desta maneira, por isso mudou, tem mais significado }\end{array}$ \\
\hline $\begin{array}{l}\text { "Passava para os meninos o que estava lá no livro, } \\
\text { achava que não precisava de mais nada, que já era } \\
\text { suficiente" }\end{array}$ & $\begin{array}{l}\text { "Agora é diferente, tenho mais conhecimento teórico e prático e não } \\
\text { fico mais presa a ele" }\end{array}$ \\
\hline $\begin{array}{l}\text { "Sempre acompanhei o livro, nunca percebi a } \\
\text { necessidade de enfocar além do que estava nele, só } \\
\text { depois que a gente passa a conhecer que percebe que } \\
\text { falta muito conhecimento." }\end{array}$ & $\begin{array}{l}\text { "Depois que a gente passa a conhecer desta forma, tudo muda e } \\
\text { sinceramente, eu nem acompanho mais o livro, e quando chego } \\
\text { neste conteúdo então, aí que eu fico a vontade" }\end{array}$ \\
\hline $\begin{array}{l}\text { "Eu ensinava do jeito como tava no livro, era só } \\
\text { teoria mesmo" }\end{array}$ & "Agora é diferente né, vou além do que está no livro" \\
\hline $\begin{array}{l}\text { "O livro era meu único suporte para trabalhar o } \\
\text { assunto" }\end{array}$ & $\begin{array}{l}\text { "Mas agora ele não é mais meu único suporte, é tanta coisa que } \\
\text { deixa a desejar, aprendi várias metodologias no curso e aplico } \\
\text { quase todas com minhas crianças }\end{array}$ \\
\hline
\end{tabular}

A História da Petrina faz parte de um dos cadernos pedagógicos do Museu de Ciências da Terra Alexis Dorofeef, e tem como personagem principal a rocha "Petrina Gnaisse", que sai em viagem, em busca de respostas sobre a sua origem e transformações.

\section{Encontros coletivos}

Participaram dos encontros coletivos, catorze dos vinte e sete educadores entrevistados. Os demais se ausentaram por motivos diversos tais como falta de tempo, indisponibilidade aos sábados, dificuldade de deslocamento por se encontrarem em outros municípios, etc.

\subsection{Primeiro Encontro: Linha do Tempo}

Para a construção da linha do tempo, as educadoras foram divididas em três grupos, de acordo com o ano de realização do curso. Nos grupos, elas tiveram a tarefa de relembrar as oficinas realizadas, seus conceitos e métodos, resgatando-as em suas práticas pedagógicas. A partir deste resgate foi feito 
um levantamento individual sobre as atividades desenvolvidas pelas participantes ao longo dos anos envolvendo conteúdos de solos. Os relatos individuais resultaram em discussões e reflexões sobre estas atividades, destacando os desafios e as potencialidades das experiências. O registro foi feito em tarjetas e cada grupo construiu a sua linha do tempo. Ao final, os grupos se reuniram e cada grupo apresentou a sua linha do tempo para os demais.

$\mathrm{Na}$ linha do tempo do grupo de 2004 as educadoras destacaram que passaram a trabalhar bastante com o entorno da escola, desenvolvendo atividades de percepção ambiental e coleta de solos com os alunos, ao mesmo tempo em que os questionavam mais, com o objetivo de torná-los mais participantes nas aulas e ativos no processo de construção do seu próprio conhecimento. Os grupos de 2005 e 2006 resgataram as oficinas na sequência em que foram oferecidas, avaliando o grau de dificuldade e apropriação conceitual e metodológica de cada uma. A partir disso, as educadoras citaram atividades que foram realizadas em suas práticas profissionais subsequentes. Notou-se que após o curso as educadoras enfocaram a temática em projetos, feiras de ciências e feiras culturais, visitas ao Museu de Ciências da Terra Alexis Dorofeef e em trabalhos com a comunidade.

\subsection{Segundo Encontro: Diagrama de Venn e Matriz de Conteúdos e Métodos}

Para a construção do diagrama de Venn as educadoras foram divididas em três grupos, utilizando o mesmo critério do primeiro encontro. As educadoras identificaram os conteúdos trabalhados em suas práticas individualmente, e através de uma discussão coletiva buscaram um consenso para estabelecer as relações entre estes com o tema solos. Os conteúdos identificados nos grupos foram registrados em círculos de diferentes tamanhos de acordo com o grau de importância (ênfase) de cada um. A palavra solos compôs o círculo central do diagrama e os círculos de conteúdos foram dispostos à sua volta em distâncias proporcionais ao maior ou menor relacionamento daquele conteúdo com o tema solos. Após a construção dos Diagramas os grupos reuniram-se em plenária para a socialização dos diagramas construídos pelos grupos.

Foram construídos três diagramas de Venn (Figura 1), onde foi possível perceber a influência das oficinas dos cursos no conjunto amplo e diversificado de conteúdos mais ou menos relacionados

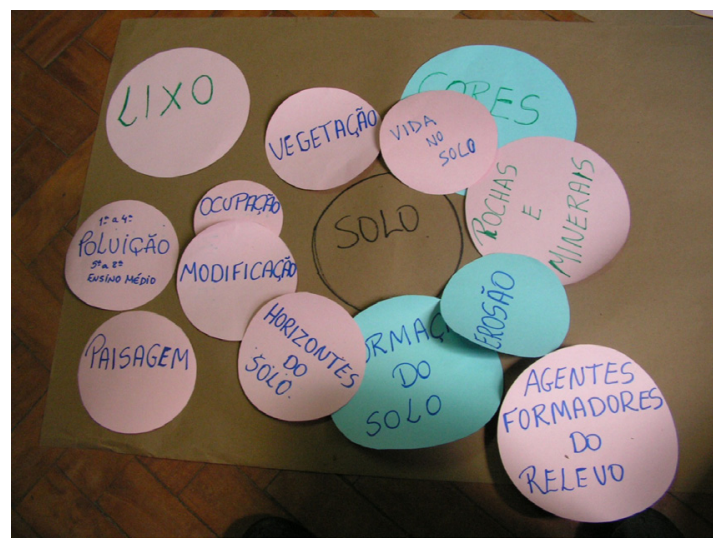

Figura 1. Aspecto do Diagrama de Venn construído pelo grupo que participou do curso de capacitação do ano de 2004

ao tema solos em suas práticas pedagógicas. No diagrama construído pelo grupo de 2004 (Figura 1a), conteúdos de formação do solo; rochas e minerais e cores do solo foram localizados muito próximos ao círculo central e foram representados pelos círculos maiores. Isso indica que esses conteúdos foram considerados fortemente relacionados ao tema solos e foram muito enfatizados em suas práticas pedagógicas, em comparação aos demais. O lixo também foi muito enfocado embora não tenha sido considerado pelo grupo como conteúdo diretamente relacionado ao solo, por ser mais amplo e envolver discussões além da temática central. No diagrama construído pelo grupo de 2005 (Figura 2) a maioria dos conteúdos identificados ficou muito próxima ao círculo central. Foram identificados três (folclore, arquitetura e arte) de pouca relação com o tema central, mas mesmo assim o tema foi trabalhado dentro destes conteúdos. As educadoras explicaram que isso é resultado da ampliação de seus conhecimentos sobre as possibilidades de aborda-

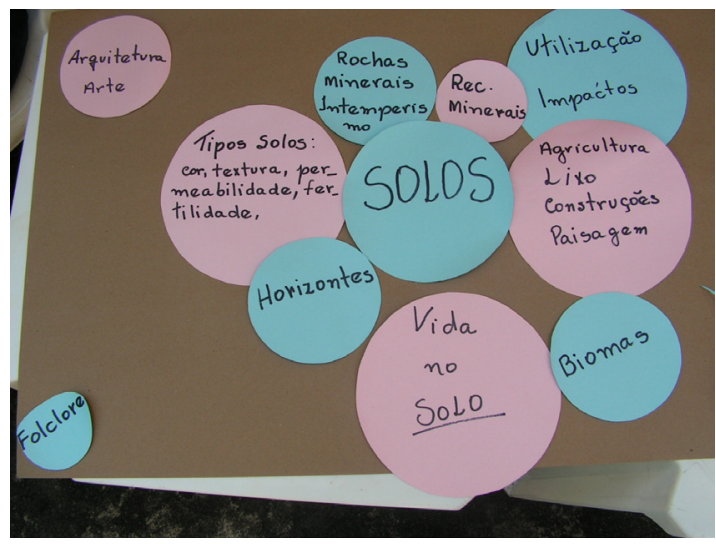

Figura 2.Aspecto do Diagrama de Venn construído pelo grupo que participou do curso de capacitação do ano de 2005 


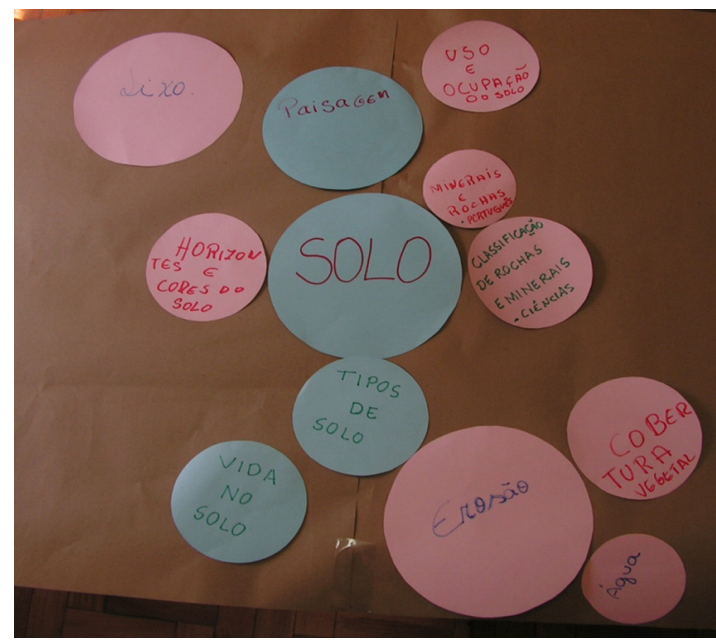

Figura 3. Aspecto do Diagrama de Venn construído pelo grupo que participou do curso de capacitação do ano de 2006

gens de solos. No diagrama construído pelo grupo de 2006 (Fig. 3), os conteúdos considerados mais relacionados com o tema central foram os tipos de solos; horizontes e cores do solo; paisagem; rochas e minerais. Temas como erosão, cobertura vegetal e água ficaram muito afastadas do tema central, mas ficaram muito próximos entre eles, indicando que estes possuem uma boa inter-relação.

Nos três diagramas apareceram alguns elementos comuns como, por exemplo, o destaque ao conteúdo de vida no solo. Este conteúdo normalmente não aparece nos livros didáticos, mas nos três diagramas ele foi reconhecido como um conteúdo importante e muito utilizado pelas educadoras. A oficina de vida no solo é uma das oficinas mais apreciadas nos cursos, comprovando-se com isso a forte influência dos cursos nas práticas profissionais das educadoras.

Para a construção coletiva da matriz de conteúdos e métodos, todos os conteúdos levantados e identificados nos diagramas de Venn foram transferidos para as colunas de uma matriz desenhada em papel pardo. Nas linhas dessa matriz, as participantes foram apontando e anotando a forma como abordaram os conteúdos, ou seja, levantaram os métodos que utilizaram para trabalhar cada um. A matriz resultante (Quadro 4) permitiu a pronta visualização dos métodos mais utilizados pelas participantes e sua relação com os vários conteúdos relacionados a solos. Foram identificados e registrados dezesseis conteúdos e treze métodos de abordagem. É um número bastante expressivo, principalmente quando consideramos os relatos das educadoras de que o tema solos era pouco abor- dado em suas práticas pedagógicas por ser difícil e complexo. Os métodos de abordagem mais utilizados foram a observação e percepção do espaço, utilizados para quinze dos dezesseis conteúdos listados. As educadoras relataram que o principal espaço utilizado foi o entorno das escolas. Isso foi despertado e estimulado por uma das oficinas do curso, que consiste na elaboração de um roteiro de observação e análise do entorno da escola. A coleta e separação de amostras foram também bastante utilizadas na abordagem de conteúdos de rochas e minerais, formação do solo, atributos do solo e vida no solo. As visitas ao Museu de Ciências da Terra Alexis Dorofeef também foram bastante utilizadas pelas educadoras: de dezesseis conteúdos citados, três foram desenvolvidos no Museu, consolidando-o como um espaço complementar ao espaço escolar (Quadro 4). A utilização ampla de diversificados métodos de abordagem no trabalho das educadoras mostra segurança e envolvimento com os conteúdos de solos e compreensão consistente de sua relação com o meio ambiente e espaços de vivência.

\subsection{Terceiro Encontro: Avaliação Coletiva}

Neste encontro, as informações e resultados alcançados com as entrevistas e com os dois encontros coletivos foram organizados em um documento e apresentados para as participantes. As participantes analisaram, avaliaram e discutiram todos os resultados alcançados nas etapas anteriores. A partir disso, destacaram e sintetizaram o conjunto de conquistas, lições e desafios relativos às suas práticas pedagógicas durante e após os cursos de capacitação em solos, resgatados e extraídos durante o processo de sistematização.

As conquistas obtidas pelas educadoras em suas práticas pedagógicas podem ser percebidas pelas respostas às questões levantadas no início desse artigo, a saber:

1. Os educadores passaram a trabalhar e abordar mais conteúdos de solos?

Sim, os educadores mencionaram em seus relatos dezesseis conteúdos em que abordam o tema solos. Antes do curso essa abordagem não acontecia, já que o tema solos era visto como difícil de ser abordado. Além do seu expressivo número, foi notável a diversidade de conteúdos levantados e a frequência com que passaram a ser abordados em sala de 


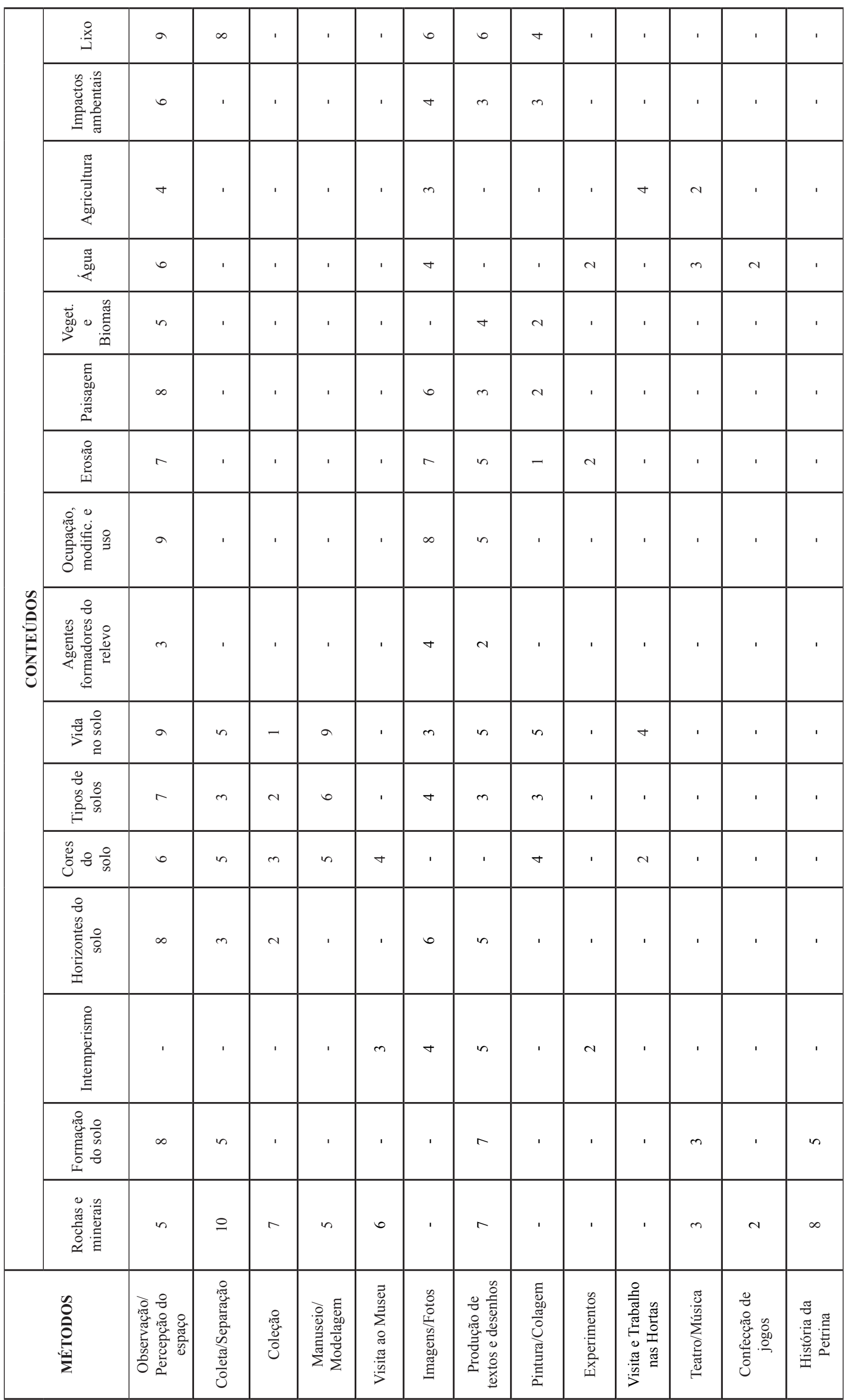


aula. Além disso, após o curso as educadoras enfocaram a temática em projetos, feiras de ciências e feiras culturais, visitas ao Museu de Ciências da Terra Alexis Dorofeef e em trabalhos com a comunidade. Também foi notável em seus relatos a superação do livro didático como único apoio conceitual e metodológico às suas aulas.

2. Os educadores conseguiram modificar a sua visão e ideia de complexidade e inacessibilidade do tema solos?

Sim, a identificação e registro do trabalho com dezesseis diferentes conteúdos de solos e a utilização de pelo menos treze metodologias representam um número significativo tanto de conteúdos como de métodos de abordagem para educadoras que de início relatavam que o tema solos era pouco abordado em suas práticas pedagógicas. As educadoras não só conquistaram maior segurança e maior envolvimento em relação ao tema como ampliaram o conjunto de conteúdos trabalhados, independentemente de serem mais ou menos relacionados a solos, assim como diversificaram os seus métodos de abordagem. Também ampliaram a integração e inter-relacionamento entre os conteúdos abordados, concretizando e efetivando a interdisciplinaridade. É importante ressaltar que a resistência inicial à abordagem de conteúdos de solos dada pela ideia da dificuldade do tema foi substituída por uma prática de resgate e valorização das experiências e conhecimentos de seus alunos, delas próprias e de outros públicos, como a comunidade, em uma perspectiva de construção dialogada do conhecimento. $\mathrm{O}$ que se observou é que os trabalhos referentes aos conteúdos de solos foram efetivamente apropriados e permaneceram nas práticas destas educadoras. Atualmente, os temas mais abordados por este grupo são: Solos e seus atributos; Rochas e Minerais; Vida no Solo e Solos e Percepção Ambiental no Entorno da Escola.

3. Os conteúdos de solos passaram a ser abordados de forma mais significativa e com a utilização de métodos mais motivadores?
Sim, os vários relatos de relacionamento do tema com o cotidiano e com os espaços de vivência da escola mostram que o tema solos ganhou significado e contextualização. E a diversificação dos métodos de abordagem mencionada na questão anterior assim como a sua utilização na abordagem de outros temas demonstram a maior motivação das educadoras, o que naturalmente se reflete em suas práticas. Assim, elas passaram a trabalhar bastante com o entorno da escola, desenvolvendo atividades de percepção ambiental e coleta de solos com os alunos, ao mesmo tempo em que os questionavam mais, com o objetivo de torná-los mais participantes nas aulas e ativos no processo de construção do seu próprio conhecimento.

4. Os educadores foram sensibilizados e compreenderam a importância ambiental dos solos? Sim, as educadoras passaram a utilizar os conteúdos de solos na abordagem das questões ambientais de forma contextualizada e bastante significativa. Elas passaram a relacionar água e solos, lixo e solos e a discutir mais aspectos de erosão e impactos relacionados. A importância ambiental dos solos foi compreendida pelas educadoras, porém o conhecimento sobre alternativas que garantam a sua conservação precisa ser ampliado e aprofundado para uma abordagem ambiental mais efetiva.

Entre outras conquistas alcançadas podemos destacar: (i) A participação de outras educadoras que não atuam especificamente na sala de aulas, como diretoras, supervisoras e uma educadora comunitária, o que foi uma conquista para elas e para os cursos. Primeiro porque permitiu a extrapolação dos resultados e impactos dos cursos para além da sala de aula, e segundo, porque a participação de diretoras e supervisoras possibilitou o trabalho conjunto nas escolas e o envolvimento de outros professores que não participaram dos cursos, fortalecendo as práticas pedagógicas escolares; (ii) A utilização mais frequente dos espaços do Museu de Ciências da Terra Alexis Dorofeef pelas educadoras. O Museu tornouse efetivamente um espaço de apoio didático para elas onde, além das visitas, algumas passaram a realizar trabalhos em parceria 
com a equipe do museu. Elas ressaltaram a importância do trabalho do Museu com o PES, que o tornou um espaço de apoio rico e dinâmico e para desenvolver diferentes atividades com seus alunos e públicos das comunidades; (iii) A ampliação de sua participação em outros espaços e instâncias, assim como de sua motivação e capacidade de intervenção em busca da transformação e aperfeiçoamento das práticas e ambientes escolares. Da mesma forma o maior uso dos espaços escolares e de seu entorno e até mesmo a reativação de hortas escolares e contribuição para a merenda escolar mostram isso.

\section{Lições, aprendizados e desafios}

As lições extraídas da sistematização participativa referem-se à importância e ao significado dos métodos dos cursos para a transformação das práticas didáticas das educadoras, à aprendizagem proporcionada pelo trabalho e pela reflexão coletiva e à importância da reflexão sobre as suas próprias práticas. Os métodos desenvolvidos nos cursos foram essenciais para as mudanças efetivadas nas práticas destas educadoras. Além de terem proporcionado um tratamento integrado dos conteúdos abordados, eles possibilitaram o aprofundamento da compreensão processual dos fatos e fenômenos relacionados aos solos e permitiram o envolvimento das educadoras com os conceitos abordados. Isso foi tão significativo que todas as educadoras passaram a utilizar os métodos praticados nos cursos, que se tornaram instrumentos essenciais em suas aulas, fazendo-as mais dinâmicas e estimulantes.

O trabalho e a reflexão coletivos proporcionados pela sistematização extrapolaram os resultados da pesquisa para além da coleta de dados e informações. A reflexão coletiva, o resgate e partilha das vivências e práticas de cada uma proporcionaram ricas trocas de experiências e novos aprendizados tanto para as educadoras como para a equipe de sistematização. Além disso, a reflexão acerca de suas próprias práticas foi uma grande lição, pois as educadoras resgataram e analisaram os avanços, os limites e os desafios de sua ação educativa.

Além destas conquistas e lições foram levantados alguns desafios relevantes para a efetivação da educação em solos nas escolas de Viçosa. O primeiro desafio levantado foi que os cursos precisam avançar nas discussões de uso e manejo sustentável dos solos, uma vez que os professores sentiram dificuldades em discutir esta questão durante o processo de sistematização. A maioria das educadoras ainda possui dificuldades para criar e aprofundar discussões sobre o assunto, restringindo a sua abordagem com os alunos. Assim, os cursos promoveram a facilitação de abordagem de conteúdos básicos de solos, permitiram a compreensão de sua importância ambiental e a percepção dos impactos de seu uso e ocupação inadequados sem, entretanto, estabelecer as relações entre estes impactos e o modo de vida da sociedade atual. Com isso, houve poucos avanços no que diz respeito à sua capacitação para a discussão e problematização do atual modelo de desenvolvimento e sua insustentabilidade, em especial no que se refere à agricultura e à ocupação urbana. As discussões inseridas no curso sobre a possibilidade de modelos de desenvolvimento mais sustentáveis tanto no que se refere ao uso de recursos minerais como de exploração agrícola, como a agroecologia, não foram apropriadas e utilizadas em suas práticas. Essas discussões, além de possibilitarem a compreensão da importância de conservar os solos, devem instrumentalizar os participantes dos cursos para a abordagem de alternativas ecológicas de uso e manejo dos solos que possam garantir a sua conservação. Esta questão ainda não foi conquistada pelo curso e se torna um desafio a ser contemplado em cursos futuros.

Outro desafio levantado pelas educadoras foi a necessidade do contínuo aprimoramento para acompanhar as transformações de conceitos e inovar métodos de trabalho e como possibilitar isso. Outro desafio para elas e, para a educação em geral, é como garantir a interdisciplinaridade e a integração com tantos outros professores que ainda não possuem a visão e trabalhos diferenciados como o delas.

Os cursos oferecidos pelo PES ainda tem como grande desafio envolver um número maior de professores e direções das escolas de Viçosa e ampliar as parcerias e apoios aos educadores que buscam realizar trabalhos com uma prática diferente daquela observada nos modelos tradicionais de transmissão de conhecimento. Os desafios levantados e sintetizados sobre estas questões foram: Como ampliar o apoio a estes educadores? Como sensibilizar o conjunto de escolas para apoiar e dar suporte para a capacitação continuada dos educadores? Como garantir o trabalho interdisciplinar nas 
escolas? Como aferir os resultados já conquistados para um universo mais amplo, que envolva além dos professores, os alunos, as famílias, as comunidades e a sociedade em geral?

Estas questões colocam outro desafio relativo à manutenção dos cursos de professores ministrados pelo Museu: a formação constante e permanente de equipes multidisciplinares para desenvolver e dar continuidade a esses trabalhos desenvolvidos pelo PES. Deve ser ressaltado que alguns dos desafios levantados extrapolam as atribuições e objetivos dos cursos, pois são desafios que se apresentam de modo geral na educação básica brasileira.

\section{Conclusões}

O processo de sistematização participativa permitiu verificar que os cursos foram importantes para ressignificar e recontextualizar as práticas pedagógicas dos educadores, uma vez que suas ações pedagógicas foram revisitadas e reconstruídas na abordagem dos conteúdos relacionados a solos. Também a relação entre teoria e prática ganhou concretude e significado para a maioria desses educadores.

A influência dos cursos de capacitação em solos extrapolou as práticas pedagógicas das professoras, na medida em que esta foi empoderadora, transformadora e libertadora: as educadoras se apropriaram de conteúdos e métodos, ampliaram a sua ação educativa para além das escolas, diversificaram e transformaram os seus espaços de atuação e libertaram-se da dependência do livro didático. Enfim, deram largos passos em busca da superação de suas limitações e na resolução dos seus desafios.

A participação das educadoras nos encontros tornou o processo de sistematização rico e fundamentado, uma vez que as contribuições individuais foram essenciais para as reflexões e discussões coletivas. Todo o processo foi enriquecedor, pois possibilitou o compartilhamento de aprendizados, trocas de experiências e reflexões sobre a prática de cada educadora. Refletir e pensar sobre a prática é importante porque se aprende a praticar melhor (Freire 2003). E através das reflexões concluiuse que a formação é um processo contínuo, de construção, desconstrução e reconstrução de conceitos, necessitando sempre de atualizações e inovações.

\section{Agradecimentos}

A todos os educadores que participaram dos cursos de capacitação em solos desenvolvidos pelo Programa de Educação em Solos e Meio Ambiente (PES), em especial às educadoras que participaram ativamente em todas as etapas da sistematização. Aos estagiários e bolsistas do PES, em especial à Mariana Carvalho, Lilian Messias Lobo e Jaime Augusto Alves dos Santos que acompanharam todo o desenvolvimento da pesquisa. Ao funcionário do Museu de Ciências da Terra, Renato Márcio Vianna pelo apoio na preparação dos encontros.

\section{Referências}

Almeida J.A. 1989. Pesquisa em extensão rural: um manual de metodologia. Brasília: MEC/ABEAS. 182p.

Cirino F.O. 2008. Sistematização participativa de cursos de capacitação em solos para professores da educação básica. Viçosa: Departamento de Solos. Universidade Federal de Viçosa. 78p. (Dissert. Mestrado).

Costa Falcão C.L. 2007. O estudo do solo sob a ótica dos livros didáticos de geografia: o seu entendimento integrado na paisagem. Univ. Regional do Cariri-URCA, Cadernos de Cultura e Ciência (2):3-9.

Falconi S. 2004. A produção de material didático para $o$ ensino de solos. Rio Claro, Univ. Est. Paulista - Inst. Geoc. Ciências Exatas. (Dissert. Mestr. Geografia).

Freire P. 2003. Professora sim tia não. Cartas a quem ousa ensinar. São Paulo: Olho d 'Água. 127p.

Geilfus F. 2000. 80 Herramientas para el Desarrollo Participativo: Diagnóstico, Planificación, Monitoreo, Evaluación. San Salvador: GTZ/II Instituto Interamericano de Cooperación para la Agricultura. 208p.

Holliday O.J. 2006. Para Sistematizar Experiências. 2. ed. Brasília: Minist. Meio Ambiente. 128p.

Lima K.E.C., Vasconcelos S.D. 2008. O professor de Ciência das escolas municipais de Recife e suas perspectivas de educação permanente. Campinas: Ciência \& Educação, 14(2):347-364.

Muggler C.C., Sobrinho F.A.P., Machado V.A. 2006. Educação em solos: princípios, teoria e métodos. Rev. Bras. Ciência do Solo. 30:733-740. 
Sistematização participativa de cursos de capacitação em solos para professores da educação básica

RESUMO : 0 Programa de Educação em Solos e Meio Ambiente, do Departamento de Solos da Universidade Federal de Viçosa oferece, desde 2004, cursos anuais de capacitação em solos para professores da Educação Básica. Após três anos consecutivos, já era possível observar os impactos da abordagem em algumas escolas de Viçosa-MG. Para analisar e refletir criticamente a influência dos cursos na prática pedagógica dos participantes desenvolveu-se pesquisa em processo de sistematização participativa, durante encontros presenciais com os participantes dos cursos de 2004, 2005 e 2006. Os resultados são apresentados neste artigo e mostram que tantoos conteúdos como os métodos desenvolvidos nos três cursos foram efetivamente apropriados pelos educadores, que valorizaram e ressignificaram o conteúdo de solos. Isso lhes deu mais segurança em sua abordagem, enriquecendo as aulas e diversificando-as com 0 uso de diferentes abordagens metodológicas, possibilitando inclusive a superação do livro didático como único apoio conceitual e metodológico às suas aulas.

Palavras-Chave: educação em solos, educação básica, formação de professores 